UnB

\title{
Para repensar o cânone: Pensamento fronteiriço e distribuição geopolítica da produção intelectual
}

\section{Resumo:}

A partir do conceito de "pensamento fronteiriço" de Walter D. Mignolo (2003), discuto a urgência da constatação de que a valoração do objeto de conhecimento e da arte, a exemplo da literatura, não está associada às predicações do objeto em si, mas exclusivamente em relação ao lugar de enunciação (de onde parte o discurso e de quem o formula). Em um contexto de colonialidade do saber, é o eu do discurso que indica o valor do objeto artístico/científico e, consequentemente, estabelece a distribuição do local legítimo de produção. E é claro que na história da produção artística e científica, o lugar de enunciação permitido sempre foi o Primeiro Mundo, onde a arte e a ciência sempre foram produzidas por brancos, mais especificamente, homens brancos. A ideia também é mostrar como Ana Maria Gonçalves em Um defeito de cor questiona o cânone literário por meio de uma poética com diversidade epistêmica e como ele torna-se o espaço para produção de "um outro pensamento" (Pensamento fronteiriço).

Palavras-chave:

Pensamento fronteiriço, Ana Maria Gonçalves, colonialidade do saber, Cânone

\section{Abstract:}

Through Walter D. Mignolo's (2003) concept of "border thinking", I discuss the urgency of the observation that the valuation of the object of knowledge and art, like literature, is not associated with the predications of the object itself, but exclusively in relation to the place of enunciation (from where the discourse comes from and who formulates it). In a context of coloniality of knowledge, it is the self of discourse that indicates the value of the artistic and scientific object and, consequently, establishes the distribution of the legitimate place of production. And it is obvious that in the history of artistic and scientific production, the place of enunciation allowed has always been the First World, where art and science have always been produced by whites, more specifically, white men. The idea is also to show how Ana Maria Gonçalves in Um defeito de cor questions the literary canon through a poetics with epistemic diversity and how it becomes the place for the production of "another thought" (border thinking).

\section{Keywords:}

Border thinking, Ana Maria Gonçalves, coloniality of knowledge, Canon 
No projeto de descolonialidade/decolonialidade do saber, Mignolo elabora uma crítica ao paradigma da modernidade tomando por base a experiência latino-americana. A crítica decolonial de Mignolo apoia-se no ideal de descolonização do conhecimento de Khatibi, crítico e romancista marroquino, que tem como fundamento dois conceitos: "a double critique" (a dupla crítica) e "une pensée autre" (um outro pensamento) (Mignolo 2003: 101). No entanto, ele cria uma conceitualização própria, designada como pensamento fronteiriço. Vale antecipar que o autor não pretendia definir uma ideia que fosse válida para todas as realidades de países que passaram pela colonização ou que fosse a única forma de pontuar uma postura não colonial do conhecimento, mas que é a que ele acredita ser uma das possibilidades para pensar a colonialidade no espaço latino-americano. Não fosse assim, ele estaria contradizendo sua própria teoria, a qual se apoia na diversidade de pensamento:

Definirei minha própria conceitualização de pensamento fronteiriço (gnose fronteiriça ou epistemologia fronteiriça). Ao fazê-lo, não estou tentando encontrar o conceito único e correto que "capte a coisa", um significante vazio (dominante) que abrange toda a diversidade de particularidades. Isso iria contra minha própria concepção de pensamento fronteiriço (...). Estaria caindo em uma visão moderna e universal de conhecimento e epistemologia, segundo a qual conceitos não estão relacionados a histórias locais, mas a projetos globais, e os projetos globais são sempre controlados por certos tipos de histórias locais. Minha concepção de pensamento fronteiriço não emerge de uma genealogia conceitual universal (...), mas parte das histórias locais dos legados espanhóis na América. (Mignolo 2013: 129-130)

Como vimos, o princípio da gnose fronteiriça ou epistemologia fronteiriça é o deslocamento do conhecimento e da epistemologia moderna e universal para a consideração do conhecimento que surge de histórias locais. Temos aí a imagem de um movimento conceitual, de um trânsito de pensamento, a saída de um pensamento excludente para um que inclui. Trata-se de uma luta "para deslocar do Primeiro para o Terceiro Mundo o locus de enunciação teórica, reivindicando a legitimidade da "localização filosófica" (Mignolo 2003: p. 162). Em se tratando da arte literária, um deslocamento similar ocorre na composição estética do romance Um defeito de cor. Esse deslocamento ocorre pelo uso da linguagem, pelo ponto de vista da narradora, pela composição das personagens, pela temática etc.

E esse giro epistêmico, no entanto, não se estabelece em um sentido dicotômico, sair de uma gnose moderna para uma gnose subalterna, buscando se apropriar de uma e excluir outra. $O$ giro epistêmico está no ato de considerar que essas epistemologias podem dialogar. O pensamento fronteiriço está em diálogo com a Modernidade, porém a partir das perspectivas subalternas. Essa é a base do pensamento fronteiriço, uma resposta epistêmica ao projeto eurocêntrico da modernidade. Acontece que nesse diálogo, o pensamento moderno deixa de ser a única referência para a produção de conhecimento, ele perde seu status de razão universal para ser uma história localizada, que dialoga com as histórias locais da América Latina sob a condição de ser adotada, rejeitada ou adaptada: 
A diferença colonial é o espaço em que a colonialidade do poder se articula. É também o espaço em que a restituição do conhecimento subalterno está sendo verificada e o pensamento fronteiriço está emergindo. A diferença colonial é o espaço em que as histórias locais que estão inventando e fazendo reais os projetos globais, se encontram com aquelas histórias locais que as recebem; É o espaço em que os projetos globais devem se adaptar e integrar ou em que são adotados, rejeitados ou ignorados. A diferença colonial é, finalmente, a localização física e imaginária a partir da qual a colonialidade do poder opera a partir do confronto entre dois tipos de histórias locais que se desenvolvem em diferentes espaços e tempos em todo o planeta. (Mignolo 2013: 8)

É nesse espaço da diferença colonial que o pensamento fronteiriço surge, em que é possível reinventar as diferenças, não para subjugá-las com classificações, pois aqui não há hierarquias de conhecimento. Portanto, com esse locus enunciativo os conhecimentos são reformulados e as experiências subalternas poderão ser descolonizadas:

A transcendência da diferença colonial só pode ser realizada a partir de uma perspectiva de subalternidade, a partir da descolonização e, consequentemente, de um novo terreno epistemológico que inaugura o pensamento fronteiriço (...). O pensamento fronteiriço sob a perspectiva da subalternidade é uma máquina de descolonização intelectual e, portanto, descolonização política e econômica. (idem: 106-107)

Para Joaze Bernardino-Costa e Ramón Grosfoguel (2016), em "Decolonialidade e perspectiva negra", a diferença entre o projeto decolonial e as teorias pós-coloniais consiste na ideia de "lugar e pensamento". Ambas as teorias apresentam a perspectiva de um espaço de fronteira que rompe binarismos, em que se identificam os limites das ideias universalistas. No entanto, é o projeto decolonial que entende que as fronteiras além de serem espaços onde a diferença colonial é reinventada, são também loci enunciativos onde os conhecimentos são produzidos a partir da perspectiva dos sujeitos subalternos, como a da mulher negra:

Aqui reside uma importante diferença entre o projeto decolonial e as teorias pós-coloniais. Essas tematizam a fronteira ou o entrelugar como espaço que rompe com os binarismos, isto é, onde se percebe os limites das ideias que pressupõem essências pré-estabelecidas e fixas. Na perspectiva do projeto decolonial, as fronteiras não são somente este espaço onde as diferenças são reinventadas, são também loci enunciativos de onde são formulados conhecimentos a partir das perspectivas, cosmovisões ou experiências dos sujeitos subalternos. O que está implícito nessa afirmação é uma conexão entre o lugar e o pensamento. (Bernardino-Costa/ Grosfoguel 2016: 19)

Com uma abordagem diferente, mas que também denuncia a postura eurocêntrica da Modernidade e pensa a descolonização do saber a partir das epistemologias vindas das histórias locais, Boaventura de Sousa Santos (2009) traz uma contribuição importante para esse debate. Para o autor, a intervenção da epistemologia ocidental descredibilizou e suprimiu 
todas as práticas sociais dos conhecimentos contrários aos interesses eurocêntricos. "Nisso consistiu o epistemicídio, ou seja, a supressão dos conhecimentos locais perpetrada por um conhecimento alienígena" (Santos 2009: 10). O epistemicídio é consequência de uma não reflexão epistemológica do contexto cultural e político da produção e reprodução do conhecimento.

Como modo de intervenção nessa epistemologia dominante que suprime a pluralidade epistemológica, Santos apresenta o conceito de "epistemologia do sul", em que o Sul é uma referência metafórica aos países oprimidos pela colonialidade do conhecimento. Então, a "epistemologia do sul" seria uma gama de intervenções epistemológicas que denunciam essa supressão, valorizam os saberes que resistiram com êxito e investigam as condições de um diálogo horizontal entre conhecimentos (Santos 2009: 13). E esses diálogos entre os saberes ele chamou de "ecologias de saberes". É uma teoria diferente da de Mignolo, entretanto cruza com o pensamento fronteiriço ao considerar a possibilidade de diálogo entre as epistemologias.

Um defeito de cor traz à baila essa interação de diferentes epistemologias, denunciando a supressão epistêmica e valorizando os saberes subalternos. Esse reconhecimento não é configurado em uma postura de aversão a outras possibilidades de epistemologias. A narrativa não aprova também a simplificação cultural por via de um purismo. Ao contrário, traz o diálogo horizontal entre os saberes para o centro da cena. Coloca em negociação mais de uma base epistemológica, mostrando as experiências de conhecimentos tradicionais e reconfigurados dos africanos e afro-brasileiros. Há o questionamento dos sentidos e epistemologias dominantes, desafiando as fundações das relações epistêmicas dominantes e imperiais e, assim, acaba por contribuir para a descolonização da arte, do conhecimento e da crítica literária, por sinalizar novos caminhos para leituras dos textos literários:

A Mãe Rosa ouvia tudo com muita atenção e quase me ofereci para tomar nota do que falavam, mas me lembrei de que nem sempre as irmandades gostam de ter suas tradições por escrito, preferindo que sejam passadas de irmã para irmã. Assim também acontecia com os cultos que, à exceção dos feitos pelos muçurumins, eram ensinados apenas oralmente, para evitar que a parte sagrada caia em mãos erradas. Acho que também era um jeito de se protegerem das autoridades, que não permitiam outro culto a não ser o dos brancos católicos. Embora a Irmandade da Boa Morte fosse fundada em torno de um culto católico, o de Nossa Senhora, havia muito das crenças africanas, segredos que só eram revelados para as irmãs. (Gonçalves 2013: 610)

Aí temos um exemplo de diálogo entre epistemologias diferentes. Há o registro de uma religião africana que mantém sua tradição viva por meio da oralidade, mas temos uma personagem inserida nessa mesma religião que domina a escrita e que se regula para não registrar esses conhecimentos sagrados. A narradora deixa clara a diferença entre os cultos africanos e católicos, mas não nega que em alguma medida, os cultos africanos receberam influências, quando diz que "a irmandade da Boa Morte foi fundada em torno de um culto católico, o de Nossa Senhora". 
Há também na narrativa de Um defeito de cor o registro do elo entre as oralidades e a escrita, sendo a primeira uma cultura tradicionalmente africana (as oralidades registradas no romance), e a segunda uma cultura branca. Na trama, o povo africano acabou por utilizar esse instrumento do branco para representar uma perspectiva fronteiriça, isto é, a escrita para os negros, de acordo com a narrativa, surge para contar as histórias dos negros, as quais antes eram ditas oralmente. Isso correu porque o tempo do negro foi roubado, o tempo de expressar sua cultura. A escrita se torna uma postura de resistência:

os africanos não gostam de pôr histórias no papel, o branco é que gosta. Você pode dizer que estou fazendo isso agora, deixando tudo escrito para você, mas esta é uma história que eu teria te contado aos poucos, noite após noite, até que você dormisse. E só faço assim, por escrito, porque sei que já não tenho mais esse tempo. Já não tenho mais quase tempo algum, a não ser o que já passou e que eu gostaria de te deixar como herança. (Gonçalves 2013: 617)

Portanto, a narrativa afro-brasileira foge de um pensamento abissal, "o pensamento moderno ocidental, o qual se caracteriza pela impossibilidade da co-presença dos dois lados da linha" (Santos 2009: 20-21). O pensamento moderno, para Boaventura de Sousa Santos, é uma linha abissal invisível, que separa de um lado ciência, filosofia e teologia e, do outro, conhecimentos incomensuráveis, incompreensíveis por não obedecerem a critérios científicos de verdade, nem assumirem a ideia do conhecimento alternativo, como no caso da filosofia e teologia (Santos 2009: 25-26). Do outro lado da linha, há a inexistência, o invisível, a ausência não dialética. É espaço que esgota o campo da realidade relevante. Nesse lado da linha encontram-se os conhecimentos populares, encontra-se nossa literatura afro-brasileira etc. Essas produções desapareceram como conhecimento relevante ou comensuráveis por se encontrarem para além do universo de verdadeiro ou falso.

Mas como vimos e veremos, essas linhas globais que dividem os dois lados têm se deslocado no âmbito ficcional por Um defeito de cor. Essas fiç̧ões trazem um pensamento "pós-abissal" (Santos 2009: 43) por considerar que a diversidade do mundo é inesgotável e que a "diversidade epistemológica do mundo continua por construir" (Santos 2009: 43).

O reconhecimento dessa diversidade epistêmica é perpassado pela necessidade de redistribuição acadêmica do trabalho científico (produção de conhecimento). E é urgente, entre tantas questões, pela constatação de que a valoração do objeto de conhecimento, a exemplo da literatura, não está associada às predicações do objeto em si, mas exclusivamente em relação ao lugar de enunciação. Em um contexto de colonialidade do saber, é o eu do discurso que indica o valor do objeto artístico/científico e, consequentemente, estabelece a distribuição do local legítimo de produção. E é claro que na história da produção artística e científica, o lugar de enunciação permitido sempre foi o Primeiro Mundo, onde a arte e a ciência sempre foram produzidas por brancos, mais especificamente, homens brancos. É o que diz Mignolo ao afirmar que o fundamento dessa distribuição "não pode ser necessariamente associado às propriedades dos objetos classificados, mas sim ao lugar de enunciação que cria a distribuição: a enunciação 
Cadernos de Literatura Comparada

Para repensar o cânone

localiza-se no Primeiro e não no Segundo ou Terceiro Mundo" (Mignolo 2003: 162).

\section{Literatura e colonialidade do saber}

Constatados os fundamentos dessa distribuição, compreendemos que quando se fala em produção de conhecimento e de arte, além do local de produção, a questão está em quem fala. A exemplo disso, temos a literatura afro-brasileira que é posicionada no lugar do silêncio na literatura brasileira, e essa, por sua vez, está apagada do cenário da história da literatura mundial. Esse silenciamento da literatura brasileira implica a localização dessa produção (Brasil) e, obviamente, a exclusão da literatura afro-brasileira da historiografia literária ocorre especialmente pela escolha do local de fala, do fato dessa produção ser realizada pelo negro. Antes mesmo da nossa literatura ser julgada por suas propriedades, ela é ofuscada por ser produzida em um país periférico ou por um autor negro. Desse modo, concordo com Mignolo quando ele afirma que a distribuição não é necessariamente relacionada ao objeto, mas ao locus de produção teórica (de onde parte o discurso e de quem o formula).

Mediante essa condição, o projeto da literatura afro-brasileira torna-se a voz do Terceiro Mundo que exige reversão de uma imagem equivocada dos afro-brasileiros e africanos no Brasil, que é produzida e sustentada pela herança colonial, isso é, reivindicam o reconhecimento de suas produções artísticas, culturais e científicas. A narradora de Um defeito de cor apresenta epistemologias para apontar que as culturas africanas são diversas e complexas. Na linguagem da narrativa de Um defeito de cor temos claramente a predominância da epistemologia iorubá, mas a narradora traz outras possibilidades a partir das experiências das personagens negras originárias de várias partes da África.

Para não ficar apenas em referências da literatura nacional, essa diversidade de representação é percebida se compararmos Um defeito de cor com Terra sonâmbula, de Mia Couto, por exemplo. O primeiro romance parte especialmente de uma epistemologia iorubá, como dito anteriormente, e o segundo prioriza uma epistemologia banta. Desse modo, por se tratar de pensamentos diferentes, a representação de crianças gêmeas em Um defeito de cor e em Terra sonâmbula é disparadamente dessemelhante; são dois romances e múltiplas Áfricas representadas:

Farida era filha do Céu, estava condenada a não poder nunca olhar o arco-íris. Não lhe apresentaram à lua como fazem com todos os nascidos da sua terra. Cumpria um castigo ditado pelos milénios: era filha-gémea, tinha nascido de uma morte. Na crença da sua gente, nascimento de gémeos é sinal de grande desgraça. No dia seguinte a ela ter nascido, foi declarado chimussi: a todos estava interdito lavrar o chão. Caso uma enxada, nesse tempo, ferisse a terra, as chuvas deixariam de cair para sempre. (Couto 2007: 70)

A lógica cultural presente em Moçambique é diferente da sociedade Savalu, reino de Daomé, atualmente República do Benim. Na cultura tradicional moçambicana (não para toda Moçambique, obviamente) o nascimento de crianças gêmeas simboliza maldição para 
a família e a comunidade, sendo necessário a morte de uma das gêmeas e o isolamento social da mãe e da filha. Já na sociedade de Savalu (no caso, para a população de origem iorubá), o nascimento de gêmeas (ibêjis) é sinal de benção e sorte para a família e toda a comunidade que as recebem em seus recintos. A presença dessas crianças pode significar prosperidade para os comerciantes:

Mas depois que a casa ficou pronta, ele seguiu viagem rumo ao norte, talvez para Natitingou, antes de saber que ela estava novamente pejada, abençoada com ibêjis, eu e a Taiwo. Ibêjis dão boa sorte e riqueza para as famílias em que nascem, e era por isso que a minha mãe podia dançar no mercado de Savalu e ganhar dinheiro. Ela dançava e as pessoas colavam cauris (Cauri: um tipo de concha usado como dinheiro) em sua testa, e quando eu e a Taiwo éramos pequenas, colavam ainda mais, pois a minha mãe dançava com nós duas amarradas ao corpo. (Gonçalves 2013: 21)

O objetivo dessas escolhas epistêmicas perpassa a tentativa de quebrar a lógica de que literatura ou conhecimento de qualidade só podem ser produzidos em determinados locais, suportes, bases epistêmicas, ou por determinado gênero ou raça:

Se, conforme a distribuição da produção científica e cultural em Primeiro e Segundo e Terceiro Mundo, alguém vem de um país econômica e tecnologicamente subdesenvolvido, essa pessoa é vista também como pouco brilhante. Seguindo então a lógica da colonialidade do poder, essa pessoa é incapaz de produzir qualquer tipo de pensamento teórico significativo, pois a teoria se define pelos padrões do Primeiro Mundo" ... De acordo com essa lógica, produzem-se teorias e ciências em países de Primeiro Mundo, onde não há obstáculos ideológicos ao pensamento científico e teórico. Assim, a ideologia da missão civilizadora ainda estava atuando na distribuição do trabalho científico entre os três mundos. (Mignolo 2003: 164)

Um defeito de cor não apenas quebra a lógica de local permitido para produzir conhecimento e de epistemologias possíveis, mas também rompe a lógica de quem deve produzi-lo. Na trama, é uma mulher negra que produz conhecimento, e o suporte é nada convencional; trata-se de escritas de memórias. Esse é o meio que ela escolhe para mostrar ao filho o que aconteceu no Brasil colônia com o povo negro. Ela produz parte da história dos negros no Brasil, o que foi ser negro brasileiro por aqui, sobre o que é ser africano em terras brasileiras; uma narradora que reflete e mapeia parte da cultura negra brasileira de modo diversificado. A protagonista do romance, ao assumir o papel de produtora do conhecimento, se posiciona como intelectual, lugar que sempre foi negado para as mulheres negras. Ana Maria Gonçalves confere poder aos eliminados e marginalizados da produção do saber e do entendimento ao colocar a África e o Brasil no mapa, não só da produção cultural, mas também da reflexão teórica, e ao apresentar a mulher negra como uma intelectual. O leitor desse romance tem acesso às referências culturais que não poderiam ser adquiridas lendo bibliografias oficiais da história do Brasil ou mesmo romances de autoria branca. 
O que pretendi dizer é que os romances, como o Ana Maria Gonçalves, assumem uma postura epistêmica e de algum modo teórica e isso faz parte do projeto de descolonização da literatura afro-brasileira, pois "quando 'narrativas literárias' são também consideradas teorias em si mesmas, a distinção entre a localização da produção teórica e cultural começa a desmoronar" (Mignolo 2003: 165). Hoje, até é admitido que países periféricos produzam cultura (literatura), mas é quase impossível aceitar que também produzam ciência (teoria). No caso da literatura afro-brasileira, temos um duplo deslocamento, pois além de ser negada por vezes o título de literatura, lhe é também negada a capacidade de teorizar. Por isso, penso que o ato de não considerar a literatura como um texto que postula uma crítica teórica é seguir um padrão rígido de teoria. Nessa perspectiva, a literatura pode assumir uma postura epistêmica e teórica e essa atitude figura uma escolha estética que afronta a elite letrada, pois apresenta uma versão do conhecimento que costuma ser classificada como subalterna.

Mediante isso, como postura de resistência, o discurso decolonial de Ana Maria Gonçalves associa a produção literária e teórica a países com heranças coloniais. Um defeito de cor relaciona personagens periféricos não apenas à produção cultural, mas à produção teórica, ou seja, a narrativa se desloca dos locus da produção intelectual do Primeiro Mundo para o Terceiro e prova que não apenas a criação literária pode ser atribuída à produção cultural do Terceiro Mundo, mas também à teoria. Assim, as práticas descoloniais evidenciadas nos romances Um defeito de cor desafia as bases do conceito ocidental de conhecimento, ao apresentar tramas com bases epistêmicas diferentes, e fomenta uma abertura para outras formas de pensar/narrar o Brasil, de ver o mundo, sobretudo no que se refere à arte e à ciência. Esses textos estão mostrando outras possibilidades de ler a vida, exibem outras bases epistêmicas, um outro pensamento:

As práticas teóricas pós-coloniais não estão apenas mudando nossas visões dos processos coloniais; mas, ao estabelecer ligações epistemológicas entre locais geoistóricos e produção teórica, estão também desafiando as próprias bases do conceito ocidental de conhecimento e compreensão. (Mignolo 2003: 165)

Até que ponto podemos concordar que a produção da teoria (epistemologia) é mais complexa que a produção literária? Considerando que as produções literárias do Terceiro Mundo dificilmente entram para o cânone universal, não seria o caso de falarmos que ambas estão em situações quase similares? Vejamos: a literatura brasileira é vista como galho da portuguesa e a portuguesa como "arbusto de segunda ordem no jardim das Musas", sendo apenas uma derivação das fontes originais, a Europa. Como bem diz o crítico Pedro Duarte acerca do pensamento de Antonio Candido em relação ao pertencimento da literatura brasileira à mundial,

ressalte-se, ainda, que o pertencimento da literatura brasileira à mundial acontece seguindo a lógica de Candido, por derivação das fontes originais. No ensaio "Literatura e desenvolvimento", ele afirma que "nossas literaturas latino-americanas, como também as da América do Norte, são basicamente galhos da metropolitanas" e acrescenta ainda que "se afastarmos os melindres do orgulho nacional, veremos 
que, apesar da autonomia que foram adquirindo em relação a essas, ainda são em partes reflexas". Emprega-se, aqui, aquela mesma famosa metáfora que aparece em Formação da literatura brasileira, em 1959, segundo a qual a "nossa literatura é galho secundário da portuguesa, por sua vez arbusto de segunda ordem no jardim das Musas". Ou seja, ela é derivada. (Duarte 2013: 193-194)

Do mesmo modo, a teoria produzida no Terceiro Mundo é considerada apenas crítica literária e não teoria, é apenas um galho da teoria ou da crítica europeia, até porque quase toda crítica europeia se passa por teoria, já que o local de produção a legitima como tal. É possível consultarmos as produções, por exemplo, da América Latina, mas o que valida a minha fala são as teorias dos grandes nomes das academias europeias. Assim, retornamos a Mignolo, que considera que uma outra vantagem, ou potencial de "um outro pensamento" (pensamento fronteiriço), é que ele permite uma nova perspectiva para uma ordem geopolítica de produção do conhecimento. Desse modo, uma das questões do pensamento fronteiriço é a defesa da distribuição geopolítica das tarefas intelectuais. O pensamento fronteiriço é a consequência dessa descolonialidade intelectual:

Filosofia precisa ser apropriada como uma palavra e uma atividade a partir da África ou da América Latina (Salazar Bondy, 1966; 1969) para interrogar a Europa e a filosofia europeia como a história local na qual esses projetos globais foram concebidos e impostos pela força ou pela sedução. Mas há, ainda um outro nível que a filosofia Africana precisa reorganizar sua tarefa além da releitura das figuras-chave dos filósofos ocidentais em sua cegueira para a diferença colonial e a colonialidade do poder. (Mignolo 2003: 98)

Diferentemente da ideia de superação evolutiva do Iluminismo ou mais especificamente na modernidade dialética do progresso de Kant, Hegel ou Marx, Mignolo apresenta a ideia que seria a alternativa para sairmos da armadilha do pensamento eurocêntrico, para superarmos os limites do pensamento territorial moderno. A opção provém do pensamento fronteiriço que prevê a "dupla crítica":

O potencial epistemológico do pensamento fronteiriço, de 'um outro pensamento' tem a possibilidade de superar a limitação do pensamento territorial (isto é, a epistemologia monotópica da modernidade), cuja vitória foi possibilitada por seu poder de subalternizar o conhecimento localizado fora dos parâmetros das concepções modernas de razão e racionalidade. Uma dupla crítica libera conhecimentos que foram subalternizados, e a liberação desses conhecimentos possibilita 'um outro pensamento' (...) Um outro pensamento" implica a redistribuição da geopolítica do conhecimento da forma como foi organizada tanto pelo ocidentalismo (enquanto imaginário dominante e autodefinição do sistema mundial moderno) como pelo orientalismo (um exemplo particular em que se localizava a diferença do mesmo), juntamente com estudo da área e o triunfo das ciências sociais na geopolítica do conhecimento. (Mignolo 2013: 131-132) 
Cadernos de Literatura Comparada

Para repensar o cânone

Para Mignolo, "um outro pensamento/ pensamento fronteiriço" não está situado no pensamento cosmopolita ou no local, mas "situa-se em todos esses, e em nenhum deles, em um território fronteiriço" (Mignolo 2013: 132). Ou seja, a produção do conhecimento deve partir de um espaço marginalizado:

\begin{abstract}
O pensamento fronteiriço é a singularidade epistêmica de qualquer projeto decolonial. Por quê? Porque a epistemologia fronteiriça é a epistemologia do anthropos que não quer se submeter à humanitas, ainda que ao mesmo tempo não possa evitá-la. A descolonialidade e o pensamento/sensibilidade/fazer fronteiriços estão, por conseguinte, estritamente interconectados, ainda que a descolonialidade não possa ser nem cartesiana nem marxista; a descolonialidade emerge da experiência da colonialidade, alheia a Descartes e invisível para Marx. (Mignolo 2017: 16)
\end{abstract}

De modo similar à ideia de Mignolo, em relação ao pensamento fronteiriço que prevê um diálogo entre o local (tradição) e o cosmopolitismo (modernidade), o filósofo e crítico literário congolês Valentin Yves Mudimbe, fala em A invenção da África: gnose, filosofia e a ordem do conhecimento (2013), de um terceiro espaço, quando discute as consequências do colonialismo no continente africano. Mudimbe afirma que a estrutura colonizadora emergiu de um sistema dicotômico e com ele algumas oposições paradigmáticas, como o tradicional versus o moderno. No entanto, uma nova estrutura foi herdada do colonialismo. Entre dois extremos (por exemplo, a tradição e a modernidade), existiria um espaço intermediário, "um espaço difuso, em que acontecimentos sociais e econômicos definem o grau de marginalidade" (Mudimbe 2013: 19). Esse espaço intermediário é o espaço da marginalidade, a "marginalidade designa o espaço intermediário entre a denominada tradição africana e a modernidade projetada do colonialismo". É claro que ambos os autores estão falando de colonizações diferentes, um da herança colonial da América Latina e o outro das experiências africanas, mas ambos pontuam um diálogo entre culturas ou epistemologias para pensar a colonialidade e a diferença colonial.

Mas o que esse espaço de marginalização nos diz sobre a condição atual da África ou parte dela? Ele é a "principal expressão do subdesenvolvimento, revelando a forte tensão entre a modernidade que é frequentemente uma ilusão de desenvolvimento e uma tradição que por vezes reflete uma imagem fraca de um passado mítico" (Mudimbe 2013: 20). Desse modo, quando se trata de estudo das culturas africanas, é necessária a sensibilidade para não ficarmos na dicotomia entre os elementos tradicionais e os modernos, pois o olhar deve percorrer o modo como esses dois elementos foram negociados para a produção de um terceiro que contém os dois, mas não é nenhum deles. Esta é a "configuração chave do pensamento fronteiriço: pensar a partir de conceitos dicotômicos ao invés de organizar o mundo em dicotomias" (Mignolo 2013: 150). Assim, o pensamento fronteiriço é, do ponto de vista lógico, um locus dicotômico de enunciação, e, historicamente, situa-se nas fronteiras (interiores + exteriores) do sistema mundial colonial/moderno (Mignolo 2013: 150).

O terceiro espaço se apresenta como o caminho para pensar as complexidades identitárias, é uma postura de afrontamento às ideias puritanas e absolutistas de raça, nacionalidade e etnias. 
É nele que os elementos culturais são negociados. A importância desse pensamento decorre da superação do pensamento territorial, o qual suplantava a ideia de superioridade raciais, culturais e históricas; é também "potencial" pela abertura para pensar as particularidades de culturas subalternizadas. Esse pensamento se aproxima da ideia de "dupla consciência" apresentada por Paul Gilroy à luz de Du Bois, que se pronuncia acerca do esforço para obter uma primeira e uma segunda identidade, que ocasionaria a "dupla consciência", ou seja, também considera a ideia de pensar a partir de dicotomias para pensar o mundo de modo plural:

Esforçar-se por ser ao mesmo tempo europeu e negro requer algumas formas específicas de dupla consciência. Ao dizer isto não pretendo sugerir que assumir uma ou ambas identidades inacabadas esvazie necessariamente os recursos subjetivos de um determinado indivíduo. Entretanto, onde os discursos racista, nacionalista ou etnicamente absolutista orquestram relações políticas de modo que essas identidades pareçam ser mutuamente exclusivas, ocupar o espaço entre elas ou tentar demonstrar sua continuidade tem sido encarado como um ato provocador e mesmo opositor de insubordinação política. (Gilroy 2001: 33)

Quem também concorda com Mignolo, Mudimbe e Gilroy quando se trata da negação do essencialismo cultural é Homi Bhabha (2003), que utiliza o conceito de "hibridismo" para falar em um terceiro espaço de negociação das culturas. Para Bhabha, todas as formas de cultura estão incessantemente em processo de hibridismo. O hibridismo é um terceiro espaço em que se pensa de modo deslocado dos espaços anteriores, que a propósito não são originais porque também já sofreram influência de outros espaços culturais, uma vez que as culturas são constituídas em relações de alteridade. Então, o espaço híbrido é aquele que foge da norma, de formas atualmente concebidas como padrão, porque esses espaços normativos não são suficientes para compreender certas exigências do pensamento produzido no terceiro espaço. Portanto, o terceiro espaço é um lugar necessário para a expressão de certas produções culturais porque admite um lugar de enunciação político e histórico provindos da perspectiva subalternizada:

É apenas quando compreendemos que todas as afirmações e sistemas culturais são construídos nesse espaço contraditório e ambivalente da enunciação que começamos a compreender porque as reinvindicações hierárquicas de originalidade ou "pureza" inerente às culturas são insustentáveis, mesmo antes de recorrermos a instâncias históricas empíricas que demonstram seu hibridismo. (...) É o Terceiro Espaço, que embora em si irrepresentável, constitui as condições discursivas da enunciação que garantem que o significado e os símbolos da cultura não tenham unidade ou fixidez primordial e que até os mesmos signos possam ser apropriados, traduzidos, re-historicizados e lidos de outro modo (...)

O novo lugar de enunciação político e histórico transforma os significados da herança colonial nos signos libertários de um povo livre e do futuro. (Bhabha 2003: 67-68)

Definido o objetivo do pensamento fronteiriço, cabe agora esclarecer o quanto Mignolo acredita nesse pensamento. $\mathrm{O}$ fato é que ele carrega um potencial, tanto epistemológico quanto 
Cadernos de Literatura Comparada

Para repensar o cânone

ético: "o potencial de 'um outro pensamento' é epistemológico e também ético: epistemológico porque é construído sobre a crítica às limitações de duas tradições metafísicas - a cristã/ ocidental secular e a islâmica" (Mignolo 2003: 104). Isto é, não existe pureza de pensamento, o que há é a diversidade e a tolerância para identificar as possibilidades de conversas entre dois pensamentos divergentes.

O potencial epistêmico do pensamento fronteiriço é visto em Ana Maria Gonçalves porque ao mesmo tempo que suas personagens aderem à tradição cristã, também estão influenciadas por outras crenças religiosas. A protagonista de Um defeito de cor, Kehinde, tem apreço pelos voduns, entidades de sua terra natal, mas também tem devoção aos orixás, entidades que conheceu com os negros de outros espaços africanos, tem fé nos santos católicos e ainda aprendeu a devotar o deus dos seus irmãos negros islâmicos. Essa personagem é a síntese de como o pensamento fronteiriço pode ser representado, é a "utopia do interconhecimento", quando se aprendem ou se absorvem outros conhecimentos sem esquecer o próprio (Santos 2009: 47). E por fim, a ética de "um outro pensamento" é manifestada nessa narrativa porque suas afirmações e teses não pretendem ser universais, nem dominadoras, uma vez que ao apresentar em sua estética a composição do pensamento fronteiriço, torna-se uma narrativa universalmente fragmentária e aberta. Assim, a descrição de "um outro pensamento" é

um modo de pensar que não é inspirado em suas próprias limitações e não almeja dominar e humilhar; (...) um modo de pensar que por ser universalmente marginal e fragmentário não é etnocida (Khatibi 1983: 19). Nisso reside o potencial ético de um outro pensamento. (Mignolo 2013: 132)

Para Mignolo, "a dupla crítica é uma estratégia crucial para a construção de macronarrativas", pois permite "pensar a colonialidade, e não apenas a modernidade, de forma livre". Um defeito de cor segue a estratégia de construir macronarrativas que não têm a pretensão de se tornar em verdadeiras ou únicas, mas que estão estrategicamente posicionadas para questionar os discursos coloniais, ao colocarem em evidência outras possibilidades de discursos, fazendo ressoar vozes silenciadas. Então, esse romance torna-se o espaço para produção de "um outro pensamento". Aponta outros trajetos para a criação literária, novas formas de pensar o estético, de pensar a crítica literária, enfim, de pensar a literatura.

Para tanto, o pensar exige mudar os termos, pensar a produção literária de autoria negra no Brasil não como sub-literatura ou literatura menor, apenas literatura que carrega suas riquezas justamente por suas particularidades identitárias (essas identidades exigem uma outra conduta de leitura, um deslocamento da lógica da crítica e teoria literária eurocêntrica) para a razão subalterna, que para Mignolo só é possível por "um outro pensamento":

(...) Na perspectiva da colonialidade. Como tais, essas macronarrativas não estão predestinadas a enunciar a verdade que os discursos coloniais não contaram. Esse passo já está incluído na dupla crítica. Na perspectiva da colonialidade, as macronarrativas são precisamente os lugares nos quais "um outro pensamento" poderia ser implementado, não para dizer a verdade em oposição às mentiras, mas para 
pensar de outra maneira, caminhar para 'outra lógica' - em suma, para mudar os termos da conversa, e não apenas seu conteúdo. (Mignolo 2013: 133)

Assim, compreendemos que a literatura afro-brasileira contemporânea não vem para negar a cultura dominante, mas para afirmar a cultura subalterna. E essa não é a antítese da anterior, é apenas diferente daquela; não dá para comparar produções que são firmadas em lógicas tão diferentes, literaturas eurocêntricas com literaturas epistemologicamente marginais na colonialidade de poder, na colonialidade do saber e na colonialidade de gênero.

E a literatura afro-brasileira é epistemologicamente marginal nessa configuração da colonialidade do poder, porque é produzida em "sociedades silenciadas" e, como sabemos, "as sociedades silenciadas', mesmo quando falam, diz Khatibi, não são ouvidas em suas diferenças" (Mignolo 2003: 108). O conhecimento proveniente de histórias locais, que não produzem, mas recebem projetos globais, é elaborado na interseção das línguas silenciadoras, como no caso de Khatibi e Glissant. Esses pensadores não receberam a mesma atenção que, por exemplo, Derrida e Foucault na França, que falam apenas a partir de língua hegemônica. Nesse sentido, o trabalho de Walter Mignolo é importante para nossas análises porque o autor se ocupa, especialmente, do "pensamento fronteiriço produzido pela última classe de intelectuais, que vive nos países originalmente colonizados e move-se entre ambos, como é o caso de Khatibi" (Mignolo 2013: 136-137) e de Mudimbe, citado anteriormente, que apesar de ser congolês e priorizar o estudo de parte do continente africano, vive nos Estados Unidos.

Do mesmo modo que esses intelectuais, Ana Maria Gonçalves apresenta um discurso fronteiriço ao produzir seu romance. Embora em língua portuguesa da América do Sul, o corpo que fala na narrativa carrega memórias diferentes dos falantes do português europeu, e, sobretudo, diferentes concepções e sensibilidade de mundo, além dos fartos vocábulos do Iorubá. "Esse movimento é, ao mesmo tempo, um esforço para desvincular da tirania da razão ocidental suas ciências e tecnologias articuladas em línguas ocidentais" (Mignolo 2003: 111) para estabelecer a razão subalterna, como se vê um exemplo em Um defeito de cor:

O meu nome é Kehinde porque sou uma ibêji e nasci por último. Minha irmã nasceu primeiro e por isso se chamava Taiwo. Antes tinha nascido o meu irmão Kokumo, e o nome dele significava "não morrerás mais, os deuses te segurarão". O Kokumo era um abiku, como a minha mãe. O nome dela, Dúróorîike, era o mesmo que "fica, tu serás mimada". Aminha avó Dúrójaiyé tinha esse nome porque também era uma abiku, e o nome pedia "fica para gozar a vida, nós imploramos". Assim são os abikus, espíritos amigos há mais tempo do que qualquer um de nós pode contar, e que, antes de nascer, combinam entre si que logo voltarão a morrer para se encontrar novamente no mundo dos espíritos. Alguns abikus tentam nascer na mesma família para permanecerem juntos, embora não se lembrem disto quando estão aqui no ayê, na terra, a não ser quando sabem que são abikus. (Gonçalves 2013: 19)

Somente nesse trecho temos a presença de oito vocábulos africanos de origem iorubá. A maioria, é nome de personagem, mas também há outros substantivos que fazem referência ao 
Cadernos de Literatura Comparada

Para repensar o cânone

modo como o povo iorubá ou parte dele percebe o mundo: "abikus" (crianças que nascem para morrer) e "ibêjis" (crianças gêmeas que são sinônimos de sorte para a família que as têm em casa), termos marcadores da crença religiosa; a presença do termo "ayê" como referência da percepção de espaço. Essas representações do pensamento africano, manifestado na linguagem, seguem em todo o romance com termos não apenas do iorubá, mas de outros grupos étnicos africanos. Essa é uma das principais estratégias da romancista para referenciar de onde parte o pensamento ou a razão epistêmica de sua obra ficcional, também é o modo de denunciar o racismo que mantém o privilégio enunciativo das línguas modernas europeias:

O racismo moderno/colonial, ou seja, a lógica da racialização que surgiu no século XVI, tem duas dimensões (ontológica e epistêmica) e um só propósito: classificar como inferiores e alheias ao domínio do conhecimento sistemático todas as línguas que não sejam o grego, o latim e as seis línguas europeias modernas, para manter assim o privilégio enunciativo das instituições, os homens e as categorias do pensamento do Renascimento e a Ilustração europeias. As línguas que não eram aptas para o pensamento racional (seja teológico ou secular) foram consideradas as línguas que revelavam a inferioridade dos seres humanos que as falavam. (Mignolo 2017: 17-18)

Diante disso, é possível compreendermos que um "outro pensamento é uma maneira de pensar sem o outro" (Mignolo 2003: 102), de libertar-se de uma ciência e arte colonial. Nesse sentido, falando de literatura afro-brasileira, o outro pensamento surge na escrita de autoria negra quando o (a) autor (a) traz para o texto as marcas de pertencimento dos povos negros, de modo mais verossímil possível, isto é, os elementos que representam seus conhecimentos, suas línguas, suas histórias, seus legados etc.

Em Um defeito de cor, esse pensar aparece sobretudo com a narrativa das cidades africanas, dos caminhos percorridos pelos negros em São Salvador, pelas reações à opressão, pelas religiões, pelo narrar do trabalho diário nas ruas para conseguir a liberdade, pela formação de organizações (espécie de sindicatos) para planejarem a liberdade em massa, mesmo que ocorra paulatinamente; na escolha das palavras em iorubá etc. Há uma tentativa clara de representação/ aproximação do pensamento dos negros. E essa tentativa é bem-sucedida, porque é apresentada de modo complexo e variado, sem negar as contradições de identidades e as influências ocidentais. "Se no início os colonos inquestionavelmente consideravam que o seu idioma era apropriado para expressar a complexa realidade do lugar ocupado, os escritores mais recentemente iniciaram uma série de questionamentos a este respeito" (Bonnici 1998: 12-13). Essa inovação linguística é o que Bhabha chamou de hibridismo, é o terceiro espaço de localização da cultura.

De pronto, pode-se falar que especialmente em Um defeito de cor o trabalho com a linguagem objetiva colocar em destaque as culturas africanas e afro-brasileira, como também revela as dificuldades de representar a realidade social das tantas possibilidades culturais. A pluralidade da linguagem empregada aponta para a crítica às ciências que pensam a partir de um monolinguismo. Essas ciências, ao tentarem ser transparentes, apenas abafam as realidades sociais e 
culturais, porque ao partirem de uma única língua (e uma língua etnocêntrica), se fundamentam em um único pensamento, ou seja, longe das configurações culturais dos países que foram colonizados:

A diferença entre as duas posições é óbvia: enquanto o monolinguísmo das ciências sociais implica a pureza de linguagem e a transparência do sujeito conhecedor, descrevendo e explicando um objeto conhecível, um outro pensamento é, pelo contrário, a opacidade através da língua como propõe Glissant ((1990) 1997: 144), numa argumentação diferente mas paralela: "A língua não tem (outra) missão a não ser aquela que lhe é atribuída pelo Estado e pela metafísica na transparência científica, isto é, sua presumida capacidade de espelhar a realidade dos mundos "social" e "natural". (Mignolo 2003: 114)

Contrariando a ideia de que uma literatura precisa ter caráter universal para ter qualidade, postulado por Antonio Candido, em Ana Maria Gonçalves encontra-se a pluralidade linguística, cultural, política e epistêmica em que predomina o espaço marginal. Até podemos falar em elementos globais, mas mudando os termos da crítica e o contexto da conversação, por exemplo, ao criarmos narrativas que pensam em línguas, temos uma forma de cultura globalizada, mas sem a razão universal, portanto trata-se de postura para descolonizar a arte literária:

Um outro pensamento torna-se uma máquina de tradução e que é ao mesmo tempo, uma forma de pensar em línguas, uma forma de globalidade (na expressão de Glissant) que opera traduzindo códigos e sistemas de signos, circulando no, sobre e sob o mundo. Ora, essa situação bilíngue, pensando por Khatibi na relação entre o árabe e o francês, será válida para qualquer outra situação bilíngue do planeta, onde o falar em línguas é, ao mesmo tempo, uma forma de conquistar poder e de descolonização do conhecimento. (Mignolo 2003: 123)

Como vimos, a descolonização da arte literária ocorre nesses moldes, pois há a introdução do iorubá em Um defeito de cor. A narrativa surge em uma interferência harmoniosa (conflitante apenas para o leitor distante desse processo cultural) entre duas epistemologias.

No romance aparece o que Mignolo chama de a "identidade na política", que é um movimento necessário de pensamento e ação no sentido de romper as grades da moderna teoria política, que é - mesmo que não se perceba - racista e patriarcal, por negar o agenciamento político às pessoas classificadas como inferiores, em termos de gênero, raça, sexualidade etc. Assim, essas mudanças de descolonização na política da criação artística suscitam uma "desobediência política e epistêmica" (Mignolo 2008: 287), ou seja, há uma criação marcada pela opção decolonial.

Na literatura afro-brasileira, especificamente em Um defeito de cor, não é difícil perceber a opção de descolonização política. A protagonista é detentora de uma visão dos acontecimentos políticos e sociais de São Salvador; ela detém o poder de narrar os fatos não oficiais, e seu saber é recebido com confiança pelo leitor. A visão dos fatos parte de uma perspectiva feminina/ feminista e negra. Não é o senhor, nem o escravo, que emerge na narrativa, são personagens 
possuidoras de consciência. Embora tenham sido escravizados por um tempo na narrativa, alcançam liberdade e autonomia, pois suas ações então centradas em enfatizar as estratégias de resistências e não em elucidar o sofrimento com o tom de incapacidade de defesa e luta. A transformação parece uma metanarrativa de emancipação. Portanto, o romance suscita uma desobediência epistêmica:

Sem tomar essa medida e iniciar esse movimento, não será possível o desencadeamento epistêmico, portanto, permaneceremos no domínio da oposição interna aos conceitos modernos e eurocentrados, enraizados nas categorias de conceitos gregos e latinos e nas experiências e subjetividades formadas dessas bases, tanto teológicas quanto seculares. Não seremos capazes de ultrapassar os limites do Marxismo, os limites do Freudismo, Lacanismo, os limites do Foucaldianismo; ou os limites da Escola de Frankfurt, incluindo um pensador fundamentado na história dos judeus e da língua alemã tão esplêndido quanto Walter Benjamin. (Mignolo 2008: 288)

O ato criacional de Ana Maria Gonçalves é também compreendido como um ato político. É uma atitude estética de "identidade em política", porque sua obra pensa de uma maneira decolonial, reflete politicamente em termos de projetos de descolonialidade, foge da razão imperial, da política imperial de identidades, especialmente por apresentar uma narradora politicamente posicionada numa perspectiva feminista e negra.

\section{NOTA}

* Maria Aparecida Cruz de Oliveira possui graduação em Letras- Lic. Hab. de Líng. Port. e Literaturas pela Universidade do Estado da Bahia (2009), mestrado em Literatura pela Universidade de Brasília (2015) e Doutorado em Literatura pela Universidade de Brasília (2019). Tem experiência na área de Letras, com ênfase em Representação Literária Contemporânea, atuando principalmente nos seguintes temas: Feminismo decolonial, representação e Literatura afro-brasileira, Infância, Literaturas Africanas de Língua Portuguesa. Integra o Grupo de Estudos em Literatura brasileira Contemporânea coordenado pela Dra . Regina Dalcastagnè. Co-autora do livro Ana Maria Gonçalves: cartografia crítica. 


\section{Bibliografia}

Antonelli, Bernardino-Costa, Joaze/ Grosfoguel, Ramón (2016), "Decolonialidade e perspectiva negra", Revista Sociedade e Estado, v. 31, n.1, p. 15-24, jan. / abr.

Bhabha, Homi (2003), O local da cultura, Belo Horizonte, UFMG [1994].

Bonnici, Thomas (1998), Introdução ao estudo das literaturas pós-coloniais, Mimesis, Bauru, v. 19 , n. 1, p. 7-23.

Couto, Mia (2007), Terra Sonâmbula, São Paulo, Companhia das Letras [1992].

Duarte, Pedro (2013), Dois tempos para a literatura brasileira: Antonio Candido, Silviano Santiago e o Modernismo. Crítica Literária Contemporânea, Viola, Alan Flávio (Org.), Rio de Janeiro, Civilização Brasileira.

Gilroy, Paul (2001), O Atlântico negro: modernidade e dupla consciência, tradução de Cid Knipel Moreira, Rio de Janeiro, Editora 34 [1993].

Gonçalves, Ana Maria (2013), Um defeito de cor, 6. ${ }^{\text {a }}$ ed., Rio de Janeiro, Record [2006].

Mignolo, Walter D. (2008), Desobediência epistêmica: a opção descolonial e o significado de identidade em política, tradução de Ângela Lopes Norte, Cadernos de Letras da UFF - Dossiê: Literatura, língua e identidade, $\mathrm{n}^{0}$ 34, p. 287-324.

-- (2003), Histórias locais/Projetos globais: colonialidade, saberes subalternos e pensamento liminar, tradução de Solange Ribeiro de Oliveira, Belo Horizonte, Editora UFMG.

- - (2013), Historias locales/diseños globales - Colonialidad, conocimientos subalternos y pensamento froterizo, tradución de Juanmari Madariaga, Cristina Veja Solís, Madrid, Akal.

-- (2017), "Desafios decoloniais hoje", in Santos, Boaventura de Sousa/ Meneses, Maria Paula (Orgs.), Epistemologias do Sul, Foz do Iguaçu, Almedina, p. 12-32.

Mudimbe, V. Y. (2013), A invenção de África: gnose, filosofia e a ordem do conhecimento, tradução de Ana Medeiros, Mangualde (Portugal), Luanda, Edições Pedago, Edições Mulemba.

Santos, Boaventura de Sousa (2009), "Para além do pensamento abissal: das linhas globais a uma ecologia de saberes", in Santos, Boaventura de Sousa/ Meneses, Maria Paula (Orgs.), Epistemologias do Sul, Coimbra, Almedina. 